\title{
A PROMESSA DE UM NOVO HORIZONTE: COMO O PROCESSO DE URBANIZAÇÃO PROMOVEU O DIREITO À CIDADE E DIMINUIU A SEGREGAÇÃO SOCIOESPACIAL NUMA FAVELA EM JUNDIAÍ
}

\section{THE PROMISE OF A NEW HORIZON: HOW THE PROCESS OF URBANIZATION PROMOTED THE RIGHT TO THE CITY AND REDUCED SOCIO-SPATIAL SEGREGATION IN A SLUM IN JUNDIAÍ}

\author{
Josué Mastrodi ${ }^{1}$ \\ Jéssica Tamires Vianna²
}

\section{Resumo}

Neste artigo procuramos mostrar como a consolidação da industrialização está diretamente relacionada à urbanização e ao surgimento de favelas e, por meio de um estudo de caso, analisamos o processo de urbanização do Jardim Novo Horizonte, novo nome da comunidade conhecida como favela do Varjão que, ao longo de aproximadamente 45 anos, desenvolveu-se paulatinamente na cidade de Jundiaí, SP. Ao longo do estudo, constatamos que a mobilização dos moradores foi importante para a construção do direito à cidade (em especial do direito à moradia), mas o fator preponderante de desenvolvimento urbano e de redução da segregação socioespacial decorreu dos interesses colaterais dos agentes do mercado imobiliário, que demandaram infraestrutura pública naquela região porque ela se trata da última fronteira de expansão urbana da cidade.

Palavras-Chave: Direito à Moradia; Direito à Cidade; Urbanização de Favela; Segregação Socioespacial; Industrialização.

\begin{abstract}
In this paper we seek to present how industrialization is directly related to the urbanization and the emergence of slums. This is shown in this case study, where it is analysed the urbanization process of Jardim Novo Horizonte, the new name of the community previously known as the slum of Varjão, which, over approximately 45 years, has progressively developed in the city of Jundiaí, SP. We affirm that the mobilization by the people who lives in that community was important to the construction of the right to the city (specially the right to housing), but it seems that a major factor for its urban development and the reduction of socio-spatial segregation derived from side interests of real estate market, that has demanded for public infrastructure in the region because it is the last frontier for urban expansion in the city.
\end{abstract}

Keywords: Right to Housing; Right to the City; Slum's Urbanization; Socio-Spatial Segregation; Industrialization.

\footnotetext{
${ }^{1}$ Professor da Faculdade de Direito e do programa de Pós-Graduação Stricto Sensu em Sustentabilidade (Pontifícia Universidade Católica de Campinas). E-mail: mastrodi@puc-campinas.edu.br

2 Bacharel em Direito pela PUC-Campinas. E-mail: jes.vianna@hotmail.com
} 


\section{INTRODUÇÃO}

O déficit habitacional se apresenta como um dos principais problemas urbanos do Brasil, de acordo com o IPEA (2013) dentre os indicadores utilizados na política habitacional, o déficit habitacional é aquele que informa à sociedade e aos gestores públicos sobre a necessidade da população no que tange à moradia, seja em função da sua precariedade ou mesmo pelo desgaste ocorrido pelo uso. Partindo desse indicador, é possível detectar a deficiência e as possíveis maneiras de resolução das adversidades que impedem que os cidadãos habitem em moradias dignas.

Pesquisa publicada no portal de internet da Câmara Brasileira da Indústria da Construção (2012), acerca do déficit habitacional nos estados brasileiros, indica que o Estado de São Paulo apresentava índices de 56.243 residências precárias, além de 642.046 residências com ônus excessivo de aluguel até o ano de 2012.

Todavia, pesquisa do IBGE (2010) contabilizou a existência de 612 favelas ano de 2000 apenas na cidade de São Paulo. De acordo com Maricato (2000, p. 30), tais resultados não podem ser considerados precisos, pois no ano de 1987 já havia registro de 1.592 núcleos periféricos.

A imprecisão dos dados ocorre por falhas metodológicas ou mesmo pela dificuldade em conhecer a titularidade da terra sobre a qual as favelas se instalam. Essas condições se apresentam como reflexo da divisão de trabalho que delimita a condição econômica da sociedade, impondo como e onde as famílias mais e menos favorecidas irão residir.

Nas últimas décadas, de acordo com o IBGE (2000), foi constatado um grande aumento no fluxo migratório para as cidades. A partir deste ponto, também foi observado o crescimento das regiões periféricas derivado desse movimento, em que aqueles que vinham para as cidades em busca de condições melhores instalavam-se nas favelas por força de seu baixo poder aquisitivo, e é nas favelas que se encontram os maiores índices de residências precárias.

Definidas como construções proibidas pela prefeitura, constituídas por aglomerados de habitações rústicas e improvisadas, comumente habitada pelos cidadãos mais pobres, as favelas também se caracterizam pela mistura de costumes, culturas, etnias e naturalidades. Entretanto, ser morador de uma favela é ser diretamente taxado de cidadão de segunda classe, pois há um estereótipo pré-fixado, verdadeiro preconceito, segundo o qual os que vivem ali não possuiriam boa índole. 
Segundo Rodrigues (1989, p. 37), as ações realizadas pelo Estado nas favelas têm basicamente duas finalidades: a sua erradicação ou a erradicação de suas características. A partir dessas ações, a sociedade em um modo geral é induzida a acreditar que tais medidas imputam consequências positivas aos favelados, que passariam a usufruir de infraestrutura e outros benefícios da urbanização, como também implicaria em melhorias para os proprietários das terras vizinhas, haja vista que teriam valorização de suas terras.

Considerando o déficit habitacional como um dos maiores problemas urbanos do Brasil, e que de acordo com o IBGE (2010), mais de 11 milhões de pessoas residem em núcleos periféricos, neste artigo temos por finalidade mostrar como o direito à moradia pode ser efetivado na favela por meio do processo de urbanização. Para tanto, será analisado o processo de urbanização da favela do Varjão, localizada no município de Jundiaí, SP, processo gradativo que vem ocorrendo desde a década de 1990.

No primeiro item deste trabalho, trataremos sobre como a consolidação global do capitalismo influenciou na urbanização dos grandes centros, principalmente os brasileiros, levando ao crescimento desenfreado e à urbanização desigual, cujo principal subproduto é a periferização das áreas mais densamente povoadas. Também abordaremos a origem da palavra favela e onde se deu seu primeiro surgimento, abordando os aspectos da segregação socioespacial decorrente da favelização.

No segundo item, a partir da análise do caso concreto do Varjão, mostraremos como a urbanização desigual pode levar ao surgimento de uma favela. Para tanto, será apresentado um breve histórico da cidade de Jundiaí e as razões que configuraram o início da favela do Varjão, bem como a maneira que a transformação por que passa tem influenciado as relações pessoais dos cidadãos que, de moradores da favela, passaram a ser moradores do bairro Novo Horizonte: o lugar é absolutamente o mesmo, mas o processo de urbanização culminou até por mudar o nome do local. No terceiro item deste texto procuramos confrontar o ponto de vista tanto dos moradores quanto dos técnicos da Prefeitura acerca da urbanização do bairro. O processo, empreendido pela Administração Municipal, ora leva em conta interesses dos moradores, ora leva em conta interesses públicos, ora leva em conta outros interesses.

Por fim, a conclusão apresenta o resultado das pesquisas científicas e pesquisas de campo, no tocante a afirmar ou não se o direito à moradia e a diminuição da segregação socioespacial podem ser efetivados por meio da urbanização da favela em que objetivo central do processo consiste na construção de unidades habitacionais, construção de escolas, postos de saúde, sistema de transportes, a fim viabilizar a regularização fundiária de interesse social. 


\section{URBANIZAÇÃO DESIGUAL}

\section{Influência da Urbanização Europeia no Brasil}

Com o advento da Constituição Federal de 1988, a dita Constituição Cidadã estabeleceu um rol de Direitos Fundamentais e também objetivos Fundamentais da República. Todavia, apenas com a Emenda Constitucional no 26, de 14 de fevereiro de 2000, que o direito à moradia foi afirmado como direito fundamental. Antes disso, apenas o direito à propriedade era assegurado, condicionado à sua função social.

Estas disposições, discriminadas nos artigos 3ㄴ, 5o e 6o da CRFB, amparam as referenciadas nos artigos 182 e 183 da mesma Constituição, que tratam mais especificamente da política urbana, buscando reafirmar o princípio da função social da propriedade, que deve ser aplicável a toda propriedade, especialmente à propriedade urbana (art. 182, §2ㅇda CRFB, o que é reafirmado pelo artigo 39 da Lei 10.257/2001, o Estatuto da Cidade). Ademais, o texto constitucional também ressalta a importância do planejamento urbano (art. 182, caput), em especial por meio do Plano Diretor, "instrumento básico de política de desenvolvimento e de expansão urbana" (art. 182, §1으), que se faz obrigatório para toda cidade com mais de vinte mil habitantes (obrigatório, também, a todas as cidades que estejam debaixo das demais hipóteses de incidência do artigo 41 do Estatuto da Cidade). ${ }^{3}$

Dentre as finalidades do Plano Diretor está o combate à especulação imobiliária. Considera-se que os instrumentos de política urbana são meios hábeis para se atingir essa finalidade. Pelo planejamento urbano, pela promoção da regularização fundiária, pelo estabelecimento de ZEIS (Zona Especial de Interesse Social), cujo objetivo é direcionar imóveis urbanos exclusivamente para empreendimentos habitacionais destinados à população de baixa renda ou mesmo para a regularização de assentamentos precários. Esse zoneamento deve induzir um padrão específico de urbanização para determinada área, ou deve impor exigências

\footnotetext{
${ }^{3}$ Art. 41 . O plano diretor é obrigatório para cidades:

I- com mais de vinte mil habitantes;

II - integrantes de regiões metropolitanas e aglomerações urbanas;

III - onde o Poder Público municipal pretenda utilizar os instrumentos previstos no § 4o do art. 182 da Constituição Federal;

IV - integrantes de áreas de especial interesse turístico;

$\mathrm{V}$ - inseridas na área de influência de empreendimentos ou atividades com significativo impacto ambiental de âmbito regional ou nacional.

VI - incluídas no cadastro nacional de Municípios com áreas suscetíveis à ocorrência de deslizamentos de grande impacto, inundações bruscas ou processos geológicos ou hidrológicos correlatos.
} 
mais brandas para áreas ocupadas irregularmente a fim de facilitar seu processo de regularização.

A área da favela do Varjão, em Jundiaí, SP, por apresentar condições precárias, foi considerada uma zona especial de interesse social, conforme a Lei municipal no 8.683/2016, ${ }^{4}$ anexo 7. Na verdade, as melhorias urbanísticas ocorridas naquele território têm acontecido há muito mais tempo, pois o estabelecimento da área como ZEIS ocorreu no ano de 2004, por meio da Lei Complementar 415.

Assim, no Plano Diretor de 2016, essa delimitação foi reforçada e serviu mais para formalizar um desenvolvimento que já tem ocorrido há décadas em favor dos moradores do local do que para promover alguma nova urbanização. Isso não significa, porém, que interesses privados do mercado imobiliário foram eliminados. Conforme verificado em nosso estudo de caso, os moradores da favela foram mantidos no território, que não obstante cresceu e se desenvolveu porque a urbanização daquele lugar também interessava ao mercado imobiliário.

Para a efetivação do direito à moradia, é necessário compreender a relação entre direito e economia, visto que, quanto mais débil a ordem econômica de um país, mais vulnerável e frágil a proteção efetiva dos direitos inerentes aos cidadãos.

A relação entre direito e economia pode ser mais bem assimilada a partir da compreensão do sistema de produção. Direitos não nascem em árvores nem caem do céu, estão intimamente relacionados com a capacidade de produção de bens necessários ao consumo. A produção, contudo, não é realizada segundo a necessidade das pessoas, mas segundo o interesse de quem produz. O proprietário (ou a classe de proprietários) sempre foi o grande definidor das regras sociais em todos os períodos históricos. O grupo dos nãoproprietários, por outro lado, sempre pleiteou por melhores condições de vida, clamando por direitos que, vez ou outra, são cristalizados na forma de normas sociais ou, mais precisamente, jurídicas (MASTRODI e DESTRO, 2015).A expropriação e a expulsão de uma parte da população rural dos campos permitiram a incorporação dos trabalhadores nos centros urbanos, criando as condições para o desenvolvimento do mercado interno e da indústria capitalista. Como consequência dessa transição, o mercado passou a ser o principal determinante e regulador da reprodução social, uma vez que os trabalhadores precisavam vender sua força de trabalho, e os arrendatários e os industriais, donos dos meios de produção respectivamente no campo e na

\footnotetext{
${ }^{4}$ Plano Diretor do Município de Jundiaí.
} 
cidade, necessitavam de mão de obra. Era o início do capitalismo industrial, que deu origem ao processo de urbanização e formação dos grandes centros.

A Primeira Revolução Industrial inglesa, ocorrida na segunda metade do século XVIII, foi um marco histórico, pois representava a ascensão do modelo capitalista, tendo em vista a substituição do trabalho artesanal pelo trabalho maquinofaturado pelas indústrias têxteis, o que possibilitou a expansão de seu comércio tanto em nível interno, considerando o número crescente da população urbana e a disseminação da ideia do consumo, quanto em nível externo, devido ao fato de terem acesso aos meios de transportes aprimorados, boas relações diplomáticas e a capacidade de fabricar produtos a baixo custo, viabilizando sua exportação a diversos países como, por exemplo, o Brasil.

Uma das consequências sociais mais impactantes foi o intenso deslocamento da população rural para as cidades, logo, o movimento migratório em massa foi mais que o suficiente para suprir a demanda de mão de obra que as fábricas necessitavam. Como consequência, os membros dessa classe operária eram submetidos a péssimas condições de vida, pois eram condicionados a jornadas de trabalho excessivas e a salários extremamente baixos. Observando assim condições piores do que quando fixados na gleba, pois antes o servo permanecia vinculado à terra independentemente de quem fosse o titular do feudo e também Ihe era permitido cultivar em algumas áreas para sua subsistência (MIRANDA, 2012, p. 15).

As transformações econômicas e sociais ocorridas a partir da revolução espalharam-se por diversos outros países ao longo dos séculos XIX e XX; a substituição do trabalho braçal pelo mecanizado e a forte divisão social de trabalho foram suas principais características, cujos limites de produção não eram mais definidos pela resistência física do operário, e sim pela capacidade de produção da máquina.

A convergência populacional aos grandes centros em busca de emprego acarretou em verdadeiro caos nas cidades, já que não havia moradias suficientes tampouco infraestrutura, higiene etc. para atender à nova demanda. O que propiciou a proliferação de doenças e a elevação dos índices de miséria e mortalidade.

Com efeito, as concentrações urbanas acompanhavam a concentração do capital (LEFEBVRE, 2011, p. 15). Assim, os indícios de urbanização dos centros cresciam juntamente com o número de pessoas que migravam para esses novos polos.

A partir de 1940-1950, o termo industrialização começa a ser utilizado. Essa definição, como aborda Milton Santos (1993, p. 29), se refere a um processo social complexo que engloba desde a formação de um mercado nacional até a expansão do consumo e, em decorrência 
dessa industrialização houve uma grande taxa de migração para os novos polos. Em um período de 40 anos (1940-1980), a população urbana multiplicou-se por mais de sete vezes.

A urbanização, atrelada à instalação de grandes empresas nos centros, foi impulsionada ainda mais com o golpe militar de 1964, pois o país, embora estivesse passando por um período ditatorial muito violento, vivenciava o chamado milagre econômico, com reflexos especialmente nas regiões Sul e Sudeste do país.

As cidades cresceram desenfreadamente, com a construção de viadutos e avenidas elas ganharam contornos definitivos, porém, sem muita preocupação com planejamento. Até mesmo cidades planejadas como Brasília ${ }^{5}$ sofreram o impacto da periferização. Houve um aumento considerável da especulação imobiliária, mas ainda assim as cidades eram atrativas, especialmente por oferecerem empregos que escasseavam cada vez mais no campo.

$\mathrm{Na}$ verdade, as cidades brasileiras jamais foram estruturalmente preparadas para receber o novo contingente de pessoas. Isso nunca foi visto como uma preocupação de ordem pública. No entanto, por força da Constituição de 1988, passou-se a compreender como dever do Estado planejar a cidade para o fim de dar condições de vida a seus moradores. Ainda que esse discurso não tenha sido posto em prática de modo eficaz, pois tal norma sempre foi considerada de natureza programática.

De todo modo, o território da cidade sempre foi ocupado segundo regras de mercado e não segundo o direito de morar. Morar não é para quem quer, mas para quem pode pagar pelo local, segundo valores estabelecidos pela especulação imobiliária e não pelo governo. Aliás, economistas sempre profetizam que é antinatural definir preços de modo a contrariar a lei da oferta e da procura, o que explica a expulsão das classes trabalhadoras para a periferia e também o surgimento de favelas. Ressaltando que não foi o processo de urbanização em si que causou a segregação socioespacial, mas sim o processo de urbanização realizado segundo a lógica do sistema capitalista:

\footnotetext{
5 "O Plano Piloto, desde a sua fundação, já era inacessível para a população de baixa renda. O projeto inicial previa a instalação de núcleos habitacionais periféricos, cuja implantação iria atender ao aumento da população. Desta maneira, as Cidades Satélites seriam construídas proporcionalmente ao crescimento da necessidade de fixação de novos habitantes. No entanto, a velocidade deste crescimento surpreendeu a todos e as Cidades Satélites e outros projetos tiveram que se adaptar à nova realidade a fim de se evitar a proliferação desordenada de núcleos em locais não previstos e sem as necessárias condições de habitação. Eles seriam núcleos planejados, divididos em áreas distintas com delimitação das quadras residenciais e comerciais, áreas determinadas para a localização de estabelecimento de ensino, hospitais, supermercados, etc, onde o predomínio seria de moradias de 'tipo popular' evidenciando suas condições de 'cidades dormitórios' e o caráter segregador da organização do seu espaço" (LOPES, 2005, p. 8033-4).
} 
Por um lado, há hipóteses de que a urbanização é necessária para o processo do crescimento nacional pelas economias de aglomeração e escala que cria, pelas oportunidades de emprego e melhoramento de posição social que oferece e, finalmente, por seu clima favorável à elaboração de ideologias progressistas. Por outro lado, porém, acusa-se a urbanização de agravar desequilíbrios socioeconômicos e definição de serviços essenciais. As pessoas reagem como se a origem, tanto das boas coisas como das más, fosse a cidade e, por consequência, devesse esta elaborar suas respostas em seu próprio interior (SANTOS, 1982, p. 181).

Tabela 1 - Total de Habitantes em Área Rural e Urbana

\begin{tabular}{|c|c|c|c|}
\hline & Total de Habitantes & Área Rural & Área Urbana \\
\hline Norte & 15.864 .454 & 4.199 .945 & 11.664 .509 \\
\hline Nordeste & 53.081 .950 & 14.260 .704 & 38.821 .246 \\
\hline Sudeste & 80.364 .410 & 5.668 .232 & 74.696 .178 \\
\hline Sul & 27.386 .891 & 4.125 .995 & 23.260 .896 \\
\hline Centro-Oeste & 14.058 .094 & 1.575 .131 & 12.482 .963 \\
\hline \multicolumn{3}{|c|}{ Fonte: IBGE (2010) } \\
\hline
\end{tabular}

Conforme indicado na tabela acima, principalmente na região Sudeste, o número de habitantes que residem na área urbana se mostra muito superior ao número dos que residem na área rural. Esses novos habitantes buscam melhores condições de vida, todavia, quando chegam às cidades, se deparam com uma realidade complexa, principalmente nas questões de moradia com aluguéis altos, imóveis ilegais, periferização e déficit habitacional.

Tais fatores são os grandes propulsores da criação das favelas pois, sem alternativas, seja por falta de condições financeiras, seja por falta de políticas habitacionais, os mais pobres ocupam os extremos das cidades, por meio de moradias irregulares, muitas vezes construídas em áreas de risco, sem chance de se instalarem em um bairro que atenda suas necessidades básicas, uma vez que tal medida é incompatível com a realidade financeira da família.

\section{Direito à Favela}

A palavra favela originou-se de uma planta provinda da região de Canudos, na Bahia (URUGUAIANA, 2011). Popularmente chamada de Faveleiro, ela cobria o morro da Província, que acabou por ser denominado morro da Favela.

Este nome deu origem às moradias precárias dos soldados que serviram na Guerra de Canudos, revolução que foi caracterizada pelo confronto entre um movimento popular de fundo sócio-religioso e o exército da República, perdurando entre 1896 e 1897. O conflito foi resultado de uma série de fatores como a crise econômica e social na região da Bahia, tendo em vista a presença de latifúndios improdutivos, as secas e o alto índice de desemprego. 
O foco da reivindicação não era contestar o regime republicano recém-adotado no país, entretanto, com a expansão do Arraial de Canudos, a imprensa, o clero e os latifundiários passaram a acusá-los disso, o que acarretou na justificação do confronto e no apoio popular.

Assim, no ano de 1897, soldados da República vindos do Rio de Janeiro se dirigiram à região nordestina para combater Antônio Conselheiro, o líder do movimento, sob a promessa de receberem dinheiro ao retornarem. No entanto, em seu regresso, acabaram por não receber o dinheiro prometido, por consequência, por não terem dinheiro para suprir suas necessidades em termos de habitação, construíram moradias rústicas nos morros da cidade.

Os primeiros soldados que retornaram ao Rio de Janeiro se instalaram no morro da Província. Considerando que as moradias constituídas na época remetiam às habitações existentes em Canudos, como alusão, a denominação favela foi adotada para aquelas construções da mesma forma como comumente se estendeu às habitações das comunidades mais carentes.

Desde então, favela faz alusão ao tipo de moradia precária, conforme definição de Abiko e Coelho (2009, p. 15):

Favela é um termo, de certa forma genérico, comumente utilizado para definir aglomerações habitacionais de baixa renda, em condição fundiária irregular, ocupação espontânea da terra e com carência de infraestrutura, mesmo que em alguns casos parte das características possa não estar presente. É muito comum que as moradias de favelas sejam compostas por cômodos pequenos, úmidos, pouco ventilados, mal iluminados, com problemas estruturais e de acessibilidade [...].

Conforme Engels (2015, p. 25-26), o surgimento das favelas é produto da escassez da moradia que tanto pode derivar das péssimas condições de habitação quanto da sua falta em si, além de ser salientada pela especulação imobiliária, ${ }^{6}$ que acaba por expulsar a classe trabalhadora dos centros, levando-os aos extremos e contribuindo também para o ônus excessivo de aluguel nas áreas mais urbanizadas.

Outrossim, o surgimento das favelas se tornou produto da expropriação da força de trabalho no campo, o que resultou em um grande fluxo migratório, além da migração, há se falar no empobrecimento da classe trabalhadora, que luta pelo direito ao uso do solo urbano por meio de ocupações irregulares.

Sem condições de adquirirem imóveis em outras localidades, os moradores da favela acabam estabelecendo uma identidade diferente dos moradores dos bairros com maiores

\footnotetext{
6 “...uma forma pela qual os proprietários de terra recebem uma renda transferida dos outros setores produtivos da economia, especialmente através de investimentos públicos na infra-estrutura e serviços urbanos" (CAMPOS FILHO, 2001, p. 48).
} 
rendas. Eles se adaptam às condições a que são submetidos e criam ali sua própria forma de cultura e lazer, se misturando com as demais pessoas, sobretudo no âmbito de trabalho.

Tais fatores intensificam ainda mais a segregação socioespacial, que é reflexo da pobreza, podendo ser exprimida por dois processos: tanto com o surgimento das favelas e como o das cidades dormitórios. Estas são caracterizadas por serem cidades pequenas e vizinhas de cidades mais prósperas. A população, sem condições de adquirir imóvel até mesmo na periferia, acaba migrando para cidades vizinhas onde ainda não ocorreu valorização imobiliária, já que ali sequer há indícios de urbanização (ROLNIK, 1988, p. 40).

Neste sentido, Milton Santos (1982), em seu livro intitulado "Ensaio sobre a urbanização latino-americana", afirma que a urbanização, ao mesmo tempo em que se faz necessária para o crescimento nacional, gerando empregos, melhorando posições sociais, também acaba sendo responsabilizada por agravar os desequilíbrios socioeconômicos, ocasionando o desemprego e a degradação da habitação. Todavia, Santos menciona em outro livro acerca do tema urbanização, que ela não é a responsável pela segregação, considerando que é apenas um reflexo do sistema capitalista e da divisão de trabalho promovida. "Quanto mais intensa é a divisão do trabalho numa área, tanto mais cidades surgem e tanto mais diferentes são uma das outras" (SANTOS, 1998, p. 52). Para Francisco Sabatini (2001, p. 165) existem três dimensões da segregação social e urbana. A primeira se relaciona às condições econômicas: é a diferença no nível de vida entre os bairros. A segunda é a geográfica: de escala ou relações, ou seja, a distância agravada pela pobreza faz com que seus moradores não tenham muito contato com pessoas de outros lugares, pois pouco saem do bairro; e a terceira é a dimensão subjetiva, que faz com que os seus moradores procurem ficar próximos aos seus semelhantes, seja por meio de critérios de classe, etnia ou religião.

No Brasil, considerando a carência econômica e social, como o aumento do desemprego e tendo em vista a especulação imobiliária que abrange as áreas centrais, grande porcentagem da população atualmente reside em favelas. Como consequência, o Poder Público tem tentado conter a proliferação deste tipo de habitação.

De acordo com Rodrigues (1989, p. 37), a atuação do Estado nas favelas pode ser definida a partir de duas propostas básicas, a primeira delas como sendo a sua erradicação por meio da remoção dos moradores, e a segunda com a liberação de áreas antes ocupadas para outros, com o objetivo de eliminar esses aglomerados que interferem no preço da terra e desvalorizam a região, ou seja, a solução está em remover a favela ou as características de favela. 
Como consequência desta transformação de espaço, nos dizeres de Engels (apud HARVEY, 2009, p.09), "uma favela é varrida daqui para reaparecer noutro lugar qualquer. Se nos opomos ao nosso estado corrente, então o único caminho radical adiante é confrontar os processos básicos que geram esse estado".

Neste contexto, considerando que o direito à moradia está contido no rol de direitos sociais previsto no art. 60 da CRFB por força da Emenda Constitucional no 26/2000; além de já estar previsto em vários tratados, convenções, pactos e agendas internacionais, constata-se que assegurá-lo vai além de sua previsibilidade em âmbito jurídico, há a necessidade de disseminar a necessidade da moradia digna no campo político e social e não apenas transferir o problema de lugar.

Destarte, o planejamento urbano, visando à urbanização, em suma não é destinado à sociedade como um todo. O planejamento acaba concentrando a maioria das benfeitorias, tanto sociais quanto comerciais, de forma a privilegiar apenas um determinado grupo, que tem fácil acesso aos bens e serviço, o que inviabiliza um planejamento democrático e igualitário, pois a influência das classes dominantes que ocupam esses espaços expulsa cada vez mais os que possuem menos renda. Isso ocorre especialmente porque as pessoas que compõem a elite acreditam que a distância desses grupos aumenta a própria segurança, bem como a presença de imóveis antigos e precários mostra o lado negativo da organização urbana, desvalorizando os imóveis vizinhos (NEGRI, 2008).

Atreladas ao planejamento urbano, existem as leis de zoneamento que direcionam o uso e a ocupação do solo. As leis que demarcam as áreas de habitação são as que mais demarcam a segregação, pois elas demarcam as áreas mais precárias, no geral as periferias, assim, morar perto do centro é sinônimo de cidadão bem-sucedido digno de respeito, enquanto morar nas extremidades é sinônimo de pobreza, violência, estereótipos que estão cada vez mais consolidados em meio à sociedade.

O bairro Varjão está situado em uma Zona Especial de Interesse Social desde 2004 por meio da Lei Complementar 415, Anexo 4; e de acordo com a Lei n. 8.683/2016, Anexo 7, Plano Diretor Atual do Município de Jundiaí que manteve o Varjão inserido em área de ZEIS, sendo assim, o projeto habitacional envolvendo esta área está relacionado com a regularização fundiária de interesse social ${ }^{7}$ e também na construção de empreendimentos destinados a pessoas de baixa renda.

\footnotetext{
7 BRASIL. Lei n. 11.977, de 7 de julho de 2009. Dispõe sobre o Programa Minha Casa, Minha Vida PMCMV e a regularização fundiária de assentamentos localizados em áreas urbanas; altera o Decreto-Lei
} 
De acordo com dados do IBGE (2010), Jundiaí possui o 110 melhor IDH do país, um resultado que decorre do processo histórico de sua formação, entretanto, mesmo sendo uma cidade rica, Jundiaí apresenta diversos indícios de periferização.

\section{A URBANIZAÇÃO JUNDIAIENSE}

\section{Histórico de Jundiaí}

Até o final do século XVII, a região em que hoje se situa a cidade de Jundiaí era habitada por povos indígenas. Os primeiros colonizadores, advindos do movimento bandeirante chegaram à região no ano de 1615, fundando o povoado de Nossa Senhora do Desterro.

Por meio da Lei Provincial no 24, de 28 de março de 1865, Jundiaí foi elevada à condição de cidade. Ao longo dos séculos XVII, XVIII e início do XIX, sua economia era basicamente fundada na produção agrícola, com destaque para o café e a uva.

Com a expansão da produção cafeeira na segunda metade do século XIX, e a criação da Ferrovia Santos-Jundiaí, a cidade se destacava como estratégica no setor ferroviário, entretanto, em decorrência de leis como a Eusébio de Queirós ${ }^{8}$ e a Lei Áurea, ${ }^{9}$ os produtores rurais foram obrigados a procurar novos trabalhadores, foi quando se deu início ao processo de imigração europeia.

A imigração, que inicialmente tinha o objetivo de substituir a mão de obra escrava no campo, acabou por estimular o crescimento comercial, industrial e a urbanização do antigo território de Jundiaí, por meio da construção de ruas, igrejas, escolas e do desenvolvimento de atividades comerciais, todavia, as principais atividades exercidas no território eram as relacionadas à Ferrovia, como por exemplo o transporte de café e de cana de açúcar.

Entretanto, as atividades relacionadas à ferrovia tiveram seu enfraquecimento em detrimento da modernização dos meios de transporte, considerando que o custo da manutenção de rodovias era bem inferior à manutenção da ferrovia e o declínio das atividades

no 3.365, de 21 de junho de 1941, as Leis n. -4.380, de 21 de agosto de 1964, n. 6.015, de 31 de dezembro de 1973, n. 8.036, de 11 de maio de 1990, e n. 10.257, de 10 de julho de 2001, e a Medida Provisória n. 2.197-43, de 24 de agosto de 2001; e dá outras providências. Disponível em: <http://www.planalto.gov.br/ccivil_03/_ato2007-2010/2009/lei//11977.htm>. Acesso em: 06 de junho de 2017.

8 BRASIL. Lei n. 581, de 4 de setembro de 1850. Estabelece medidas para a repressão do tráfico de africanos no Império.

${ }^{9}$ BRASIL. Lei n. 3.353, de 13 de maio de 1888. Declara extinta a escravidão no Brasil.. 
agrícolas, cumulado ao processo acelerado de industrialização. Assim, em meio a este contexto, surge em Jundiaí, na década de 1970, uma favela denominada Varjão.

A partir deste ponto, é possível observar que os caminhos da urbanização vão ao encontro da segregação, pois enquanto Jundiaí incentivava a chegada das indústrias na cidade por força da elaboração do PLANIDIL (Plano de Incentivo e Desenvolvimento Industrial) possibilitando a criação de um espaço para comportar as indústrias, conhecido atualmente como Distrito Industrial, criado por meio da Lei Municipal n. 1598/69, disponibilizando incentivos e benefícios fiscais para suas instalações, concomitantemente surgia bem próxima a esta área, a região a favela do Varjão, que até a década de 1990 não era servido sequer por sistema de transporte coletivo.

Outro fator que evidencia a segregação foi a instalação da CSJ no ano de 1998 (Cia de Saneamento de Jundiaí), que teve seu local de instalação definido de forma arbitrária, instituída na região do Varjão sem que nenhum morador fosse consultado, obrigando-os a conviver com o odor e com a consequente desvalorização da área que já não era valorizada.

Neste contexto, os movimentos organizados do bairro e associação dos moradores passaram a reivindicar por melhores condições de vida e moradia.

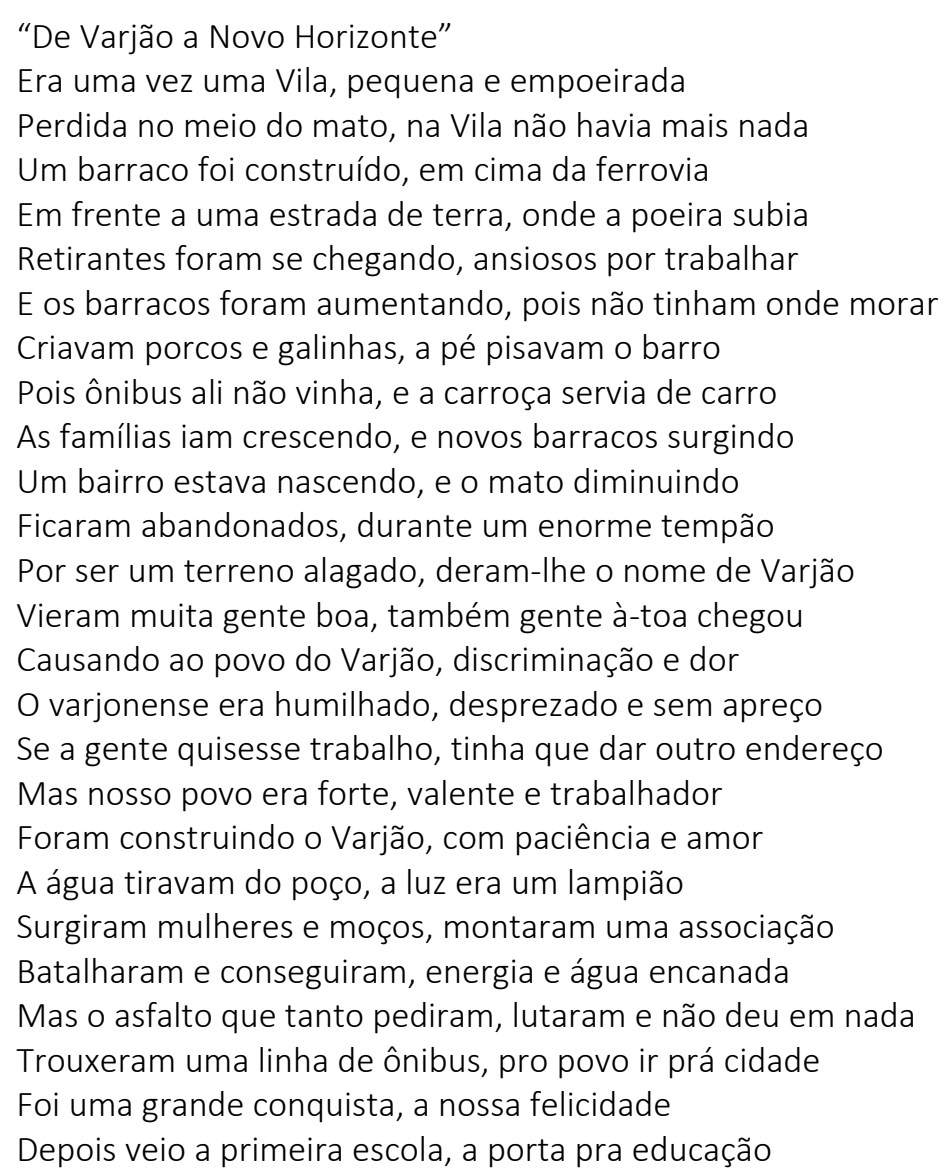


A Cléo Nogueira Barbosa, a mais bela flor do Varjão Mas o povo foi se acomodando, e os governantes idem O Varjão seguia aumentado e as necessidades também Pois o bairro que era só um, cresceu e não foi de uma vez Passou a se dividir, em Varjão um, dois e três Até que alguém teve a ideia, "o nosso azar tá no nome" Vamos dizer que o Varjão, se chama Novo Horizonte Novas forças foram se chegando, para nos trazer um renovo A Cáritas Diocesana, e a Casa da Fonte (do povo) O bairro seguia crescendo, pra nós isso não era mal Com a Fazenda Grande e C.D.H.U., Almerinda e Residencial Mas nosso povo coitado, seguia comendo pó Sentindo-se abandonado, sem sorte, sem líder e só Surgiram novas lideranças, lutando tal qual os de antes Montaram nova associação, União do Novo Horizonte Por ser um grupo combativo, com protestos bem organizados Conseguiram seu objetivo, o asfalto tão desejado Hoje temos quatro escolas, duas estaduais, duas EMEBs Um centro pra jogar bola, um posto de saúde e uma creche Hoje os bairros ao nosso lado nos fazem um só povo-irmão Quem antes era desprezado, da cidade hoje é sensação Pois tem distrito industrial, e todos querem morar aqui Região do Novo Horizonte, orgulho de Jundiaí."

O poema, escrito pelo professor Eliezer Barbosa, morador e professor do Jardim Novo Horizonte, retrata a realidade vivenciada pelos moradores daquele bairro, problemas de infraestrutura, educação, saneamento básico entre outros, apresenta a dificuldade da implementação eficaz e igualitária das políticas públicas.

Harold Laswell (apud SOUZA, 2006, p 24), considerado um dos fundadores da área de políticas públicas, introduziu o conceito de que essas políticas consistem em decisões analíticas que visam a responder aos seguintes questionamentos: "quem ganha o quê, por que e que diferença faz". A partir dessa premissa, é papel fundamental do governo elaborar seu planejamento a fim de atender as necessidades da população por meio da implementação, execução e avaliação das políticas públicas.

Como visto, o conceito de periferia está relacionado ao distanciamento, à falta de acesso às condições sociais, econômicas e espaciais do centro, características inerentes à região do Varjão, criado em meio ao processo de falência da Ferrovia Paulista S.A. (FEPASA).

\section{A Consolidação do Varjão}

O bairro Varjão está localizado em área da antiga ferrovia da Cia. Sorocabana, antes pertencente à Fazenda Ermida, que no século XVIII era muito conhecida por causa do engenho 
de açúcar e por ser fundamental no quadrilátero do açúcar formado por Itu, Campinas, Piracicaba e Jundiaí.

A partir da análise de Valderrama (2008), que trata acerca da Fazenda Ermida, com a morte dos proprietários da fazenda, os seus herdeiros venderam todo o terreno e em 1905, o novo proprietário Eloy Chaves, viu naquelas terras a facilidade do escoamento de mercadorias graças à sua posição geográfica e ao entrocamento ferroviário, tal visão do fazendeiroempresário, impulsionou a industrialização de Jundiaí, pois além de da exportação de café e eucalipto, em 1910, comprou a Companhia Fiação e Tecidos São Bento S.A, que se transformou na S.A. Industrial Jundiaiense, a primeira indústria de tecelagem da cidade.

A partir do final da década de 1960 e início de 1970, houve uma decadência nas atividades realizadas na Fazenda, reflexo de uma adaptação, da implantação de melhoramentos na forma de cultivo, que passou a voltar-se inteiramente para a exportação. A consequência dessa modernização foi o declínio da Ferrovia, o que obrigou os até então trabalhadores da fazenda a migrarem para outras cidades ou mesmo encontrarem um novo local para sua moradia e novo trabalho para sua subsistência.

A linha férrea sorocabana, ao longo dos anos, passou por inúmeras Companhias até sua estatização pela Ferrovia Paulista S.A (FEPASA) no ano de 1971. Em seu processo de falência, o trecho da antiga área da linha Sorocabana foi abandonado. Nessa conjuntura o Varjão foi formado, uma vez que os trabalhadores precisavam de um espaço de terra para se reestabelecerem.

Pelas falas dos moradores, em trabalho de campo realizado, os residentes mais antigos do bairro relataram que os trabalhadores do campo moravam nas terras do proprietário da fazenda, trabalharam durante anos, entretanto não acumularam nenhum bem. Ao serem demitidos, tinham apenas duas alternativas, tentar a sorte e vender sua força de trabalho nos grandes centros industriais como São Paulo e Campinas, que estavam em ascensão industrial, ou ocuparem alguma área abandonada para tentar reconstruir a vida.

Assim, os que permaneceram em Jundiaí, iniciaram as construções de suas casas por meio de mutirões, se empenhando na construção de barracos sobre os trilhos com o material abandonado que ali mesmo se encontrava.

O processo de ocupação desta área resultou em inúmeros conflitos pois, mesmo com a desativação da linha férrea sorocabana, enquanto os trabalhadores, advindos em sua maioria do Paraná e do Nordeste construíam suas casas com o auxílio de mutirões no decorrer da madrugada, os funcionários que faziam a segurança da ferrovia desativada, que ainda pertencia 
à administradora FEPASA, desmanchavam as construções durante o dia. Esse empasse perdurou por aproximadamente 4 meses, até que em decorrência do declínio total da administradora da ferrovia, os funcionários passaram a não mais fiscalizar a área, como consequência abandonaram os trilhos, a estação, e a ocupação pelos moradores foi efetivada.

O nome Varjão foi atribuído pelos próprios moradores, em referência à área de várzea daquele trecho da ferrovia, que era alagada por se encontrar bem próxima ao leito do Rio Jundiaí, inserida em área de APP (área de preservação permanente).

Considerando que os moradores não tinham condições financeiras de sair daquele local, bem como não queriam deixar suas famílias, a favela não se conteve, sua expansão originou o Varjão II e o Varjão III. Outro fator que impulsionou a permanência no Varjão era a esperança de adquirir a propriedade da terra através da usucapião. Atualmente o Varjão (I, II e III) tem aproximadamente $7 \mathrm{~km}$ de extensão por 80 metros de largura ao longo do ramal da ferrovia.

Mediante o Decreto n. 10.580, aprovado em 06 de março de 1989, o município determinou a delimitação dessa área pública Estadual visando a contenção da favela, visto que a existência dessas moradias precárias desvalorizava a região além de ser objeto de comercialização de moradias irregulares. Embora houvesse penalidade prevista em lei aos que infringissem esta norma municipal, a inserção do decreto municipal no ornamento jurídico não modificou a situação, a favela continuou se expandindo e as moradias continuaram a ser comercializadas, devido à dificuldade de fiscalização.

\section{DE VARJÃO A NOVO HORIZONTE}

\section{A urbanização vista de dentro}

Um pouco da história do bairro pode ser contata por meio da entrevista realizada com a Sra. Nilma Luzia da Silva Caldeira, moradora do bairro há 25 anos. Nilma comprou um terreno no bairro Varjão mesmo sabendo que este era irregular e mesmo sem perspectiva da documentação que atestaria que aquele local era seu por direito. Todavia, considerando o alto índice da especulação imóbiliária em Jundiaí, aquele era o único terreno que a família, constituída por seu cônjuge e dois filhos menores, teria condições de comprar, além de ser perto do local de trabalho do marido. 
Quando se mudou para lá, o transporte era muito precário, o ônibus passava somente três vezes ao dia, e passava apenas no Novo Horizonte 2 e 3, nunca no 1 . A distância até o centro não era grande, mas o trajeto demorava aproximadamente duas horas.

Não havia mercado, posto de saúde, o esgoto era a céu aberto, a água era de poço, a energia elétrica era clandestina e o barro e a poeira eram sempre muito presentes, pois quando chovia nem pessoas tampouco os ônibus conseguiam adentrar no bairro; e quando não chovia, percebia que diversos moradores desenvolviam doenças respiratórias tendo em vista o excesso de poeira.

No ano de 1992, chegou ao bairro a primeira escola, uma escola de ensino básico infantil, a antiga EMEF, atual EMEB Profa Cléo Nogueira Barbosa. As outras crianças do ensino fundamental e os jovens estudantes do ensino médio tinham que ir andando à escola mais próxima, que ficava a cerca de 4 km de distância, pois não tinham dinheiro para a condução e, mesmo que tivessem dinheiro, o horário do ônibus muitas vezes não era compatível com o horário de entrada e saída da escola.

A dificuldade do acesso à escola era motivo de evasão escolar, pois as mães, que trabalhavam no mesmo horário em que os filhos estudavam, não tinham como acompanhá-los no trajeto que, por sua vez, muitas vezes não era completado pelos alunos. Deste modo, observando a dificuldade dos estudantes, frequentemente os motoristas de ônibus, em vez de transportar os moradores adultos, davam carona para as crianças até certo trecho para facilitar sua locomoção diária.

Nos últimos dez anos, Nilma tem constatado uma grande evolução no bairro, como a instalação de escolas estaduais e municipais. Todavia, a infraestrutura veio muito devagar e com muito esforço da população, pois o Novo Horizonte ainda era tido como a região dos "invisíveis" visto que o diálogo com o poder público era praticamente impossível, como reforçou o presidente da Associação dos Moradores, o Sr. José Bessa, que relatou que as tentativas de informar as necessidades do bairro, na maioria das vezes, eram reiteradamente frustradas, pois eles eram tidos como favelados e invasores e, consequentemente, sem direitos de reivindicar por melhorias.

Então, objetivando um retorno das autoridades como meio de chamar a atenção para aquela região, os moradores passaram a proibir a entrada dos ônibus no Novo Horizonte, o que acarretou em um transtorno no transporte público municipal. Com a crise do ônibus, jornais apareceram no bairro, dando mais visibilidade àquele povo. Esta atitude não resolveu todos os problemas, no entanto, fez com que eles ao menos fossem ouvidos. 
A instalação de um loteamento particular bem próximo ao Novo Horizonte também auxiliou na urbanização, pois houve dificuldade de venda dos terrenos desse loteamento, dificuldade esta atribuída ao fato de os lotes terem uma favela irregular na vizinhança. A solução para o problema do loteamento passou a ser a regularização e a urbanização da favela. Com isso, mais pessoas, agora os empresários do mercado imobiliário, passaram a requerer junto ao poder público a reforma urbanística da área.

Os empresários do distrito industrial, área que faz divisa com o bairro, também sentiam a necessidade da urbanização, pois sua mão de obra, precipuamente proveniente do Novo Horizonte, tinha muita dificuldade em se locomover ao trabalho, já que não havia uma rede de transporte que abrangesse a área.

Todos esses fatores colaboraram para a maior visibilidade e preocupação do poder público para a região, que começou a se cercar de empreendimentos legalizados, como habitações do CDHU, o Residencial Almerinda, que é um loetamento particular, e o Distrito Industrial, restando apenas o Jardim Novo Horizonte sem a devida regularização fundiária e com todos os problemas de infraestrutura.

O crescimento do bairro foi exponencial: houve um aumento no número de habitantes, aumento de mão de obra para empresas, aumento no índice de violência, no entanto, os próprios moradores acreditam que houve a diminuição do preconceito após a mudança de nome de Varjão para Novo Horizonte: a população residente começou a acreditar que possuía uma nova identidade. Houve um aumento da autoestima dos moradores, que começaram a se preocupar mais com a estética das casas, se organizando para mudar o aspecto do bairro, a exemplo da mudança do nome.

A Sra. Nilma relata que as pessoas que moravam no Varjão tinham vergonha e um certo receio de falarem que eram de lá. A moradora deu um exemplo que, no ponto de ônibus no centro, além de serem chamados de "povo do pé vermelho", tendo em vista que o bairro não era asfaltado, ouvia piadas do tipo "quando passa o ônibus do Varjão, o ponto esvazia", cumulado com as chacotas, as pessoas davam passos para trás toda vez que ônibus se aproximava, mesmo que o ponto estivesse vazio. Quando os moradores do bairro encaminhavam currículos, modificavam o endereço e quando diziam a verdade em um momento posterior chegavam até a perder o emprego em decorrência do local onde moravam, o que também foi confirmado pelo Sr. José Bessa, que já sofreu discriminação por este motivo.

O Sr. José Bessa, que é morador do bairro há 29 anos, relata que, quando chegou ao Novo Horizonte, havia cerca de 500 famílias residindo no local e que atualmente são cerca de 
8.898 pessoas em 3.204 famílias cadastradas. Isto se tornou reflexo do inchaço urbano, considerando que os primeiros moradores trouxeram seus parentes e constituíram família no bairro.

Com o advento do processo de urbanização e o surgimento dos bairros vizinhos, o custo de vida se tornou mais oneroso, compras de supermercado, por exemplo, não compensam ser realizadas no bairro, os moradores preferem sair do Novo Horizonte para fazerem as compras do mês.

Nos bairros vizinhos Almerinda Chaves e Residencial, o aluguel também aumentou. No Novo Horizonte não há oficialmente pessoas morando de aluguel, pois desde que começou o processo de urbanização vige sobre a área a Lei de Contenção, ${ }^{10}$ pela qual a locação residencial é coibida, assim como a construção e a ampliação de residências no bairro. As ampliações e as locações que acontecem são clandestinas e, portanto, não possuem registro. No entanto, como o custo de vida do entorno aumentou, pode-se pressupor que houve, também por ali, aumento do custo de aluguéis.

Mas apesar das inúmeras coisas que ainda podem ser feitas para melhorar, os moradores se sentem atualmente satisfeitos por residirem naquele local, pois as mudanças que ocorreram foram muito significativas para quem acompanhou o processo desde o início.

\section{O Processo de Transformação}

Grande parte das conquistas alcançadas pelos habitantes do Varjão se deu a partir da mobilização da associação dos moradores. As primeiras mudanças, como água encanada e energia elétrica, surgiram no final da década de 1980 e início da década de 1990 em decorrência da iniciativa popular, ou seja, por meio da mobilização local na criação da Associação do Novo Horizonte.

O asfalto das ruas, que era um dos pedidos mais obstinados, somente foi atendido no início do século XXI, após inúmeras reivindicações, reclamações por meio da mídia e solicitações a vereadores e, do mesmo modo como o asfalto em si, o nome da via principal do bairro também foi uma conquista, pois como forma de promover o interesse público, queriam nomeála com o nome de um político da cidade, o que resultou em um plesbicito e por maioria dos votos, a rua continuou carregando a história daquele bairro, chamando-se Estrada Municipal do Varjão.

10 JUNDIAÍ. Lei Municipal n. 5.163, de 24 de agosto de 1998 - Regula contenção de favelas e fixa à Fundação Municipal de Ação Social - FUMAS competências correlatas. 
A partir dessas reivindicações, o bairro foi contemplado com centros comunitários mantidos pela Fumas (Fundação Municipal de Ação Social) e administrados pela comunidade; escolas municipais, creches, escolas estaduais, centro de assistência social, posto de saúde, ONG's como a Cáritas Diocesana de Jundiaí, que é um órgão mantido pela Igreja Católica com o objetivo de desenvolver oficinas e cursos profissionalizantes, a Fundação Antônio Antonieta Cintra Gordinho, onde são ministradas aulas de reeducação escolar de 1a a 4⿳亠口冖 série, e a Rede Socioassistencial Jardim Novo Horizonte.

A organização dos moradores também se modernizou, criaram-se redes virtuais ${ }^{11}$ para propagar ideias, promover debates, veicular reivindicações e divulgar os acontecimentos do bairro.

Todavia, o foco principal da reivindicação era a luta pela legitimação da terra. Embora houvesse a grande necessidade de urbanização para que existissem condições mínimas de habitação naquele local, a legitimação era um ascpecto essencial para os moradores como um todo. Nesse contexto, os líderes locais junto com a Associação União do Novo Horizonte, iniciaram no ano de 2006 o processo judicial coletivo para a regularização fundiária.

A reação do Poder Público ao se deparar com esta iniciativa foi delimitar a área do Varjão como bem imóvel municipal, o que não diferiu na atitude dos moradores que estavam buscando a regularização por meio da usucapião coletiva. Entretanto, os moradores acabaram descobrindo, após o ajuizamento a ação, que as terras embora não pertencessem não poderiam pertencer a Jundiaí ou ao Estado de São Paulo, eram bens públicos pertencentes à União.

Os moradores do Varjão, após orientação da Secretaria do Patrimônio da União (SPU), constataram que, embora estivessem ocupando aquelas terras há mais de 30 anos, cumprindo um dos requisitos para a ocupação por meio da usucapião coletiva, as terras não poderiam ser usucapidas justamente por serem bens públicos federais.

Diante dessa situação, também orientados pela SPU, os moradores tentaram contato direto com os representantes da União, contato este realizado por meio de carta e requerimento, no entanto, sem respostas até a presente data. No conteúdo da carta e do requerimento, os moradores indagaram, sob a representação do presidente da Associação, o Sr. José Bessa, sobre a possibilidade de compra das terras, visto que a posse por meio da usucapião não seria permitida.

\footnotetext{
${ }^{11}$ Página do Facebook: Realidade Novo Horizonte; Blog do EdiCarlos, Coletivo Vetor Oeste. Acesso em 6 de junho de 2017.
} 
Mesmo após algumas conquistas e a atuação de instituições governamentais e nãogovernamentais, o Varjão ainda enfrenta dificuldades decorrentes da segregação. A desigualdade social, o tráfico de drogas, a violência e a falta de acessibilidade aos serviços públicos. Assim, a partir dessas constatações surgiu a Rede Socioassistencial do Jardim Novo Horizonte, que reúne os representantes dessas instituições com o objetivo de analisar as dificuldades que sofrem a população local. Tais entidades articulam e encaminham propostas de melhoria para a comunidade e para os bairros adjacentes.

Uma das maiores consequências da criação dessa Rede foi a participação popular, que deixou de ser exclusivamente reivindicatória, para interferir diretamente na gestão do poder público e na produção socioespacial da área, pois tanto as instituições quanto os moradores são incentivados a interpor suas propostas de melhoria.

A criação da EJA (Educação de Jovens e Adultos) no bairro é um exemplo concreto da atuação da rede, pois diagnósticos levantados pelas entidades envolvidas constataram o interesse significativo de jovens acima de 16 anos de continuar seus estudos incompletos do ensino fundamental. A partir dessa iniciativa, no ano de 2010 começaram as aulas de ensino fundamental e básico nas escolas EMEB Ivo de Bona e EMEB Cleo Nogueira.

O art. 137 da Lei Municipal n. 7.858/2012 incentiva a produção de interesse social pela inciativa privada, permitindo o loteamento ou conjunto de edificações com área mínima de 150 $\mathrm{m}^{2}$ e frente mínima de 7,50 m em qualquer imóvel da macrozona urbana (com exceção daqueles situados nas Zonas de Conservação Ambiental Urbana). Todavia, para obter estes benefícios, cada empreendimento deve destinar no mínimo 15\% das unidades geradas para utilização ou comercialização da Fumas, ou de outro órgão municipal ou estadual competente.

A lei ainda define que estes empreendimentos deverão ser executados em parceria com a Fumas, desde que atendam também os seguintes critérios: localização adequada; características físicas satisfatórias; atendimento da demanda da população de baixa renda; e demanda por lotes ou habitações de interesse social na região onde serão implantados. Nestes casos, o objetivo, além de fornecer uma moradia digna ao munícipe, também visa a dissociar a imagem de "favelado" do cidadão pobre, promovendo sua vivência no centro.

O projeto de urbanização do Jardim Novo Horizonte foi realizado por intermédio do programa "Minha Casa, Minha Vida", que é um programa federal de financiamento de moradias populares, e do governo estadual com recursos do projeto "Casa Paulista", juntamente com o FAR (Fundo de Arrendamento Residencial), um programa do governo federal em parceria com 
os estados e municípios, cujo objetivo foi a produção de unidades habitacionais destinadas a famílias com a renda de até $\mathrm{R} \$ 1.600,00$.

Assim, foram construídos 1088 apartamentos na Zona Especial de Interesse Social em que o Varjão está localizado por meio de todos esses programas supracitados sob a administração da equipe da Fumas e a Secretaria de Obras de Jundiaí.

Esse projeto de urbanização foi de grande dimensão, portanto, realizado em etapas. A etapa inicial foi a de desadensamento, objetivando a abertura de vias. Para tanto, houve a necessidade da desapropriação e demolição de casas para viabilizar a construção dos 1088 apartamentos de $50 \mathrm{~m}^{2}$, que seriam destinados $50 \%$ para os moradores do bairro e a outra metade para a população em geral, no entanto prioritariamente para os moradores da cidade que recebiam auxílio-aluguel. ${ }^{12}$

O bairro era formado basicamente pela avenida principal, a Estrada Municipal do Varjão, e mais duas paralelas a essa rua, com pelo menos 5 travessas que dão acesso a essas ruas principais.

No ano de 2010, havia um projeto básico, porém por falta de verba ficou parado e apenas foi retomado no ano de 2013. Neste novo projeto, a rua principal seria alargada, para aproximadamente 40 metros de largura, contaria com duas pistas expressas de três faixas, ciclovias, local para passeio e 34 travessas.

Entretanto, em meio à execução do projeto surgiu um problema com o empreendimento Minha Casa, Minha Vida. Tais moradias foram construídas para atender a população da faixa 1, ou seja, o salário bruto familiar não poderia ultrapassar $\mathrm{R} \$ 1.600,00$ (um mil e seiscentos reais). Porém, como não havia um cadastro atualizado da área, não foi identificado, antes do início das obras, que grande maioria das famílias do bairro ganhava mais que esse valor.

Assim, tendo em vista que a desapropriação de algumas casas era necessária para a abertura das vias propostas pelo projeto, os assistentes sociais e engenheiros da Fumas estiveram diante de um impasse, considerando que, se tirassem essas famílias de suas residências, estas estariam impossibilitadas de se mudarem para o apartamento, pois não atendiam ao critério de renda.

\footnotetext{
12 JUNDIAÍ. Lei n. 8.122, de 19 de dezembro de 2013. Autoriza concessão do "Auxílio-Aluguel" às famílias em situação habitacional de emergência; dá outras providências; e revoga as leis 7.638/11, 7.815/12 e $7.965 / 12$.
} 
Como todas as casas demarcadas no projeto para demolição (pois construídas onde, segundo o projeto, traçaram-se as ruas) necessariamente precisariam ser desocupadas, visto que o Varjão é uma reta contínua, contendo acessos à rua principal apenas por meio de pequenas vielas, essa desapropriação se tornou um empeço, uma vez que o projeto já estava em andamento e não poderia deixar de ser concluído por este motivo.

No começo de 2015, foi realizada a atualização cadastral, tornando-se possível conhecer a realidade local. Assim, com a coleta dos dados, houve a identificação das famílias que moravam fora da área em que havia necessidade de desocupação que, sobretudo possuíam a renda familiar de até $\mathrm{R} \$ 1.600,00$ e tinham o interesse de morar nos apartamentos.

A partir dessa identificação, as famílias interessadas iriam para os apartamentos e deixariam suas casas para as famílias que moram nos locais que precisam ser desapropriados e recebem mais do que $\mathrm{R} \$ .1600,00$. O problema nessa permuta foi que nem sempre a qualidade da residência era compatível com a anterior, porém, essa foi a opção para viabilizar o projeto que já havia sido iniciado.

O objetivo principal do projeto foi garantir uma moradia digna aos moradores pobres do bairro e da cidade como um todo, transformando a favela em um bairro com mais ruas, melhor infraestrutura e casas regularizadas. Realocando os moradores que moravam em área de risco, em zonas de APP (área de preservação permanente de córrego), e também os que residiam debaixo da linha de alta tensão, mesmo com o risco iminente de morte.

Mesmo com o impasse da permuta, de acordo com o relato do engenheiro da Fumas, o Novo Horizonte é um bairro promissor, que ainda irá se desenvolver bastante, uma vez que o vetor oeste, o chamado vetor de expansão da cidade, é o único lugar de Jundiaí em que ainda há espaço para a expansão física.

\section{CONCLUSÃO}

A promessa de um Novo Horizonte foi concedida aos moradores do Varjão. O projeto de urbanização trazido pela proposta de transformar a favela em bairro tentando garantir uma moradia digna aos cidadãos daquele local apenas foi possível em vista dos movimentos sociais dos moradores e, também, do interesse do mercado imobiliário por melhorias nesse espaço da cidade.

Embora a urbanização apareça como resposta e meio de garantir o processo de reprodução capitalista, ela surge não com a finalidade de eliminar o problema e sim de 
transferi-lo de lugar, pois remodelar o bairro não significa apenas modificar sua estrutura, mas sim as condições de vida de uma sociedade.

Nesse sentido, a periferia não se apresenta como consequência, mas como a forma de inserção na totalidade da produção do espaço num plano simultâneo, ou seja, a favela não é uma consequência do sistema capitalista, mas sim parte dele, pois esta simultaneidade possibilita a compreensão das desigualdades socioespaciais ilustrada pela contraposição de riqueza e pobreza, periferia e centro, subdesenvolvido e desenvolvido. A partir dessas dualidades, é possível observar que a coexistência delas é necessária para a manutenção do modo de produção capitalista e da divisão social do trabalho.

O processo de transformação da favela traz, com a mudança da qualidade de vida, o aumento do custo de vida e uma consequente taxação inédita sobre os moradores para a manutenção da infraestrutura. Contas de luz, água, tevê a cabo, passam a ser cobradas.

Torna-se um meio termo entre a conquista de serviços sem a conquista de direitos, pois ao mesmo tempo em que adquirem os serviços a que tanto almejavam, continuam sendo marginalizados por não possuírem dinheiro para a manutenção desses serviços, consequentemente, continuam sem seu direito à dignidade, pois ainda são vistos como favelados.

Como consequência, ocorre novamente o processo de migração já ocorrido anteriormente, as pessoas menos favorecidas necessitam procurar um novo local para morar, locais mais afastados do centro, locais sem infraestrutura, locais sem as condições mínimas de educação e saúde.

Uma pesquisa referente ao Mercado Imobiliário realizada pelo Secovi-SP (2014) aponta um crescimento de aproximadamente $60 \%$ no número de lançamentos imobiliários nos últimos 5 anos na cidade de Jundiaí. Essas unidades habitacionais estão localizadas em sua maioria no centro, ao longo da Rodovia Anhanguera e na Região Oeste do Município, o chamado vetor de expansão onde se localiza a região do Novo Horizonte.

A análise sobre o preço de venda girava em torno da demanda, que se concentra significativamente nos intervalos entre $\mathrm{R} \$ 190 \mathrm{mil}$ a $\mathrm{R} \$ 350 \mathrm{mil}$ até o ano de 2014. Nota-se claramente que o município vem passando por um forte processo de valorização imobiliária, influenciado pela demanda que irradia a partir da Capital, a cerca de $50 \mathrm{~km}$ de distância.

O vetor Oeste é o único local da cidade que possui espaço físico para expansão, logo, tem sido objeto de especulação imobiliária. Aliás, parece-nos que esse vetor de expansão urbana, local onde os grandes lançamentos imobiliários têm ocorrido na cidade de Jundiaí, foi o 
grande catalisador da melhoria da infraestrutura do Varjão, que nem Varjão é mais. A urbanização da favela, muito provavelmente, não teria ocorrido da forma que ocorreu se não houvesse expansão do mercado imobiliário ao seu redor. Urbanizar a favela era necessário para a valorização dos lançamentos imobiliários havidos naquela região da cidade, uma das poucas em que ainda há espaço físico para incorporação e construção de novos apartamentos de alto padrão.

De todo modo, a delimitação da Zona Especial de Interesse Social, objetivando a construção de moradias a famílias de baixa renda, parece-nos que foi igualmente determinante para manutenção dos moradores do Varjão no local. Não fosse a ZEIS, o mais provável seria a expulsão dos moradores do local e, em vez da urbanização da favela, haveria sua derrubada para construir um bairro para pessoas de alta renda.

\section{REFERÊNCIAS BIBLIOGRÁFICAS}

ABIKO, Alex Kenya; COELHO, Leandro de Oliveira. Urbanização de Favelas: Procedimentos de Gestão- Programa de Tecnologia de Habitação. Porto Alegre: Habitare, 2009.

CÂMARA Brasileira da Indústria da Construção. Déficit Habitacional no Brasil. 2012. Disponível em <http://www.cbicdados.com.br/menu/deficit-habitacional/deficit-habitacional-no-brasil>. Acesso em 20 de maio de 2017.

CAMPOS FILHO, Candido Malta. Cidades brasileiras: seu controle ou o caos. 4 ed. São Paulo: Studio Nobel, 2001.

ENGELS, Friedrich. Sobre a questão da moradia. Tradutor Nélio Schineider. BoiTempo Editorial, 2015.

LEFEBVRE, Henri. O direito à cidade. Tradução Rubens Eduardo Frias. 5a ed. 3a reimpressão. São Paulo: Centauro, 2011.

HARVEY, David. A Liberdade da Cidade. Tradução Anselmo Alfredo, Tatiana Schor, Cássio Arruda Boechat GEOUSP - Espaço e Tempo, São Paulo, n. 26, 2009, p. 09-17.

IBGE, INSTITUTO BRASILEIRO DE GEOgRAFIA E. ESTATístiCA. Censo Demográfico 2010 Resultados do Universo - Aglomerados Subnormais. Disponível em: <http://www.ibge.gov.br/home/estatistica/populacao/censo2010/aglomerados_subnormais_in formacoes_territoriais/informacoes_territoriais_tab_xls.shtm>. Acesso em 08 de junho de 2017.

IPEA, INSTITUTO DE PESQUISA ECONÔMICA APLICADA. Coletiva: Déficit Habitacional. 2013 disponível em <http://www.ipea.gov.br/portal/index.php?option=com_content\&view=article\&id=20656>. Acesso em 7 de junho de 2017. 
LEAL, Roger Stiefelmann. A Propriedade como Direito Fundamental, breves notas introdutórias. Revista de Informação Legislativa, Brasília, n. 49 n. 194 abr/jun 2012, p. 53-64.

LOPES, Marcio Alves; COSTA, Valéria Grace. Segregação e Periferização em Cidades Planejadas o Caso de Brasília. Anais do X Encontro de Geógrafos da América Latina - 20 a 26 de março de 2005. Universidade de São Paulo, p. 8030-8044.

MARICATO, Ermínia. Urbanismo na periferia do mundo globalizado. Metrópoles brasileiras. São Paulo em Perspectiva. Outubro/ dezembro 2000, p. 21- 33. Disponível em <http://www.scielo.br/pdf/spp/v14n4/9749.pdf>. Acesso em 09 de junho de 2017.

MASTRODI, Josué. DESTRO, Larissa Lauri. Sobre as causas da mudança de fundamentação das normas sociais: de normas religiosas a normas jurídicas. Direito e Práxis. Rio de Janeiro, v. 06, n. 12, 2015, p. 76-103. Disponível em http://www.epublicacoes.uerj.br/index.php/revistaceaju/article/view/15292/14035. Acesso em 9 de junho de 2017.

MIRANDA, Fernando Silveira Melo Plentz. A Mudança de Paradigma Econômico, a Revolução Industrial e a Positivação do Direito do Trabalho. Revista Virtual Direito Brasil. v. 6, n. 1, 2012, p. 01-24. Disponível em <http://www.direitobrasil.adv.br/arquivospdf/revista/revistav61/artigos/fer.pdf>. Acesso em 9 de junho de 2017.

MOVIMENTO NEGRO DE URUGUAIANA (Uruguaiana). Origem / Significado da palavra favela. 2011. Disponível em: <http://movimentonegrouruguaiana.blogspot.com.br/2011/10/origemsignificado-da-palavra-favela.html>. Acesso em 20 de maio de 2017.

NEGRI, Sílvio Moisés. Segregação Sócio-Espacial: Alguns Conceitos e Análises. Coletânea do Nosso Tempo. Rondonopólis: Ed. 8, v. VII, 2008, p. 129-153.

OLIVEN, Ruben George. Urbanização e Mudança Social no Brasil. Centro Edelstein de Pesquisas Sociais, 2010.

RAMALHO, Carlos. Classe Dominante $x$ Classe Dominada. 2010. Disponível em: <http://www.carlosramalho.com.br/2010/02/classe-dominante-x-classe-dominada.html>. Acesso em 23 de maio de 2017.

RODRIGUES, Arlete Moyses. Moradia nas Cidades Brasileiras. São Paulo, Editora Contexto, 1989.

ROLNIK, Raquel. O que é cidade. São Paulo: Brasiliense. 1988.

SABATINI, Francisco. Transformação urbana e dialética entre integração e exclusão social: reflexões sobre as cidades latino-americanas e o caso de Santiago do Chile. In.: OLIVEIRA, M. Demografia da exclusão social. Campinas, Ed. Unicamp, 2001, p.169-188.

SANTOS, Milton. A Urbanização Brasileira. São Paulo, Editora Hucitec, 1998.

Ensaios sobre a urbanização latino-americana. SP: Hucitec, 1982. 
SECOVI-SP Estudo do mercado imobiliário de Jundiaí. 2014. Disponível em: $<$ http://www.secovi.com.br/files/Arquivos/estudo-do-mercado-imobiliario-de-jundiai2013.pdf>. Acesso em 23 de maio de 2017.

SOARES, Isabelle Oliveira; AZEVEDO, Maria de Lourdes Pinheiro; STEPHAN, Ítalo Itamar Caixeiro; CARVALHO, Aline Werneck Barbosa; ARANTES, Paulo Tadeu Leite. A instituição de ZEIS na legislação municipal: estudo de seis cidades médias de Minas Gerais. Revista de Pesquisa em arquitetura e urbanismo, v. 2 n. 15, 2012, p. 21-37. Disponivel em: <http://www.revistas.usp.br/risco/issue/view/4110>. Acesso em 23 de maio 2017.

SOARES, Nicolau. Zeis e direito à moradia: as leis que alguns escolhem ignorar. 2012. Disponível em: $\quad$ http://www.redebrasilatual.com.br/blogs/desafiosurbanos/2012/02/zeis-e-direito-amoradia-as-leis-que-alguns-escolhem-nao-ver>. Acesso em 23 de maio de 2017.

SOUZA, Celina. Políticas Públicas: Uma revisão da literatura. Sociologias. Porto Alegre, ano 8, no 16, jul/dez 2006, p. 20-45.

VALDERRAMA, Berna Valentina Bruit, et al. O caso da Fazenda Ermida em Jundiaí [SP]: contribuição do café na configuração da paisagem cultural. Campinas: Revista Labor \& Engenho, v.2, n.1, 2008, p.52-61. Disponível em: http://labore-unicamp.blogspot.com.br/2010/10/laboreunicamp.html. Acesso em 06 de junho de 2017.

WOOD, Ellen Meiksins. As Origens Agrárias do Capitalismo. Artigo publicado originalmente em Monthly Review. v.50, n 3, jul/ago de 1998 Trad. Lígia Osório Silva. p. 12-29. Disponível em http://www.ifch.unicamp.br/criticamarxista/arquivos_biblioteca/artigo6612_merged.pdf.

Acesso em 28 de maio de 2017.

\section{Documentos oficiais}

BRASIL. Lei no 581, de 4 de setembro de 1850. - Estabelece medidas para a repressão do tráfico de africanos no Império. Disponível em <http://www.planalto.gov.br/ccivil_03/leis/LIM/LIM581.htm>. Acesso em 06 de junho de 2017.

Lei no 3.353, de 13 de maio de 1888. - Declara extinta a escravidão no Brasil. Disponível em <http://www.planalto.gov.br/ccivil_03/leis/LIM/LIM3353.htm>. Acesso em 06 de junho de 2017.

Lei no 11.977, de 7 de julho de 2009. Dispõe sobre o Programa Minha Casa, Minha Vida PMCMV e a regularização fundiária de assentamentos localizados em áreas urbanas; altera o Decreto-Lei no 3.365, de 21 de junho de 1941, as Leis $n^{\circ}$ ㅇ 4.380, de 21 de agosto de 1964, 6.015, de 31 de dezembro de 1973, 8.036, de 11 de maio de 1990, e 10.257, de 10 de julho de 2001, e a Medida Provisória no 2.197-43, de 24 de agosto de 2001; e dá outras providências. Disponível em: <http://www.planalto.gov.br/ccivil_03/_ato2007-2010/2009/lei/l11977.htm>. Acesso em 06 de junho de 2017.

JUNDIAÍ. Lei n. 5.163, de 24 de agosto de 1998 - Regula contenção de favelas e fixa à Fundação Municipal de Ação Social - FUMAS competências correlatas. Acesso em 23 de maio de 2017.

Lei n. 8.122, de 19 de dezembro de 2013 - Autoriza concessão do "Auxílio-Aluguel" às famílias em situação habitacional de emergência; dá outras providências; e revoga as leis 7.638/11, 7.815/12 e 7.965/12. Acesso em 23 de maio de 2017. 
Plano Local de Habitação de Interesse Social, 2015. Disponível em <http://www.habitacao.sp.gov.br/secretariahabitacao/plano_local_de_habitacao_de_interesse __social.aspx>. Acesso em 28 de maio de 2017.

Trabalho enviado em 17 de junho de 2017.

Aceito em 09 de setembro de 2017. 